Kotsopoulos, et al. The diagnosis dilemma: Dyslexia and visual-spatial ability

\title{
THE DIAGNOSIS DILEMMA: DYSLEXIA AND VISUAL-SPATIAL ABILITY
}

\author{
Donna Kotsopoulos \\ Huron University College \\ Joanna Zambrzycka \\ University of Toronto \\ Samantha Makosz \\ Wilfrid Laurier University \\ Emma Asdrubolini \\ Jovana Babic \\ Olivia Best \\ Tara Bines \\ Samantha Cook \\ Natalie Farrell \\ Victoria Gisondi \\ Meghan Scott \\ Christina Siderius \\ Dyoni Smith \\ Wilfrid Laurier University
}

\begin{abstract}
Visual-spatial ability is important for mathematics learning but also for future STEM participation. Some studies report children with dyslexia have superior visual-spatial skills and other studies report a deficit. We sought to further explore the relationship between children formally identified as having dyslexia and visual-spatial ability. Despite our best efforts, and despite recruiting from a large potential sample population, we were unable to secure a sufficient amount of participants for statistical power. Thus, our findings consider the ethical dilemma of diagnosis; namely, (1) how do children come to be tested for disabilities? And, (2) what are the potential implications, mathematical or otherwise, for children who have disabilities but are not formally identified? This report has important implications for children with disabilities and for educators.
\end{abstract}

Key words: Dyslexia, formal identification, visual-spatial ability

Contact Author: Donna Kotsopoulos, Ph.D., Provost and Dean, Faculty of Arts and Social Science, Huron University College. Email: dkotsopo@ huron.uwo.ca

Donna Kotsopoulos is the Provost and Dean, Faculty of Arts and Social Science, Huron University College, London, Ontario. Her research explores mathematical cognition across the lifespan and organizational change, leadership and resource allocation in post-secondary institutions. This research is funded by the Natural Sciences and Engineering Research Council of Canada (NSERC) and the Social Sciences and Humanities Research Council of Canada (SSHRC). 
Visual-spatial ability is comprised of the following subcomponents: spatial visualization, mental rotation, and spatial perception (Linn \& Peterson, 1985). It involves the ability to perform movements of various two- or three-dimensional figures and to mentally combine, transform, and move these figures to produce a new design (Casey et al., 2008; Clements, 2004). The research demonstrating the importance of visual-spatial ability in children is compelling. Numerous studies support the notion that visual-spatial ability promotes and is linked to mathematics learning and enhances the possibility of an individual participating in science, technology, engineering, and mathematics (STEM) careers (Lubinski, 2010; Newcombe, 2010; Tolar, Lederberg, \& Fletcher, 2009; Wai, Lubinski, \& Benbow, 2009). Noteworthy in this growing body of research is the finding that visual-spatial ability is malleable; that is, it can be taught and children can show improvement over time (Uttal et al., 2013).

Our initial aim in this research was to explore the relationship between visual-spatial ability and children formally identified with "dyslexia." Approximately 4 to $10 \%$ of the population is estimated to have dyslexia (Aleci, Piana, Piccoli, \& Bertolini, 2010; Osisanya, Lazarus, \& Adewunmi, 2013; Snowling \& Melby-Lervåg, 2016). Dyslexia is defined as "a pattern of learning difficulties characterized by problems with accurate or fluent word recognition, poor decoding, and poor spelling abilities" (American Psychiatric Association, 2013, p. 67). Aleci and colleagues (2010) have proposed that individuals with dyslexia may also have a general impairment of spatial perception whereby a crowding effect occurs in the reading of texts. However, some studies report that individuals with dyslexia have superior visual-spatial ability (Wang \& Yang, 2011) while others suggest that no significant differences exist (Duranovic, Dedeic, \& Gavrić, 2015). The research is also rather scant with younger elementary students (age 8 to 10), which was the intended foci age of this research.

Our interest in exploring the relationship between visual-spatial ability and dyslexia was motivated by the conflicting research, the proposed importance of visual-spatial ability to STEM participation, and the highly malleable nature of visual-spatial ability. As we explain shortly, despite our best efforts, we were unable to secure a sufficient amount of participants to create a statistically reliable sample, despite our research-based estimates of a potential sample population. Consequently, our findings had less to do with dyslexia and visual-spatial reasoning and more to do with the dilemma of diagnosis; namely, (1) how do children come to be tested for disabilities? And, (2) what are the potential implications, mathematical or otherwise, for children who have disabilities but are not formally identified?

We state up front that we do not take the opportunity to challenge constructions of disability. This was not our intention and nor the focus of the unintended shift in foci. Given the importance of mathematics education to a child's future, ensuring that all children have access to mathematics education, or access to additional supports if a disability is identified, should be a common global concern for teachers, educators, and policy makers. Consequently, reflecting on the outcomes of our recruitment efforts we believe is an important commentary that may serve to advance discussions of equity and school-based processes.

\section{Dyslexia and Visual-spatial Ability}

Wang and Yang (2011) looked at visual-spatial abilities in Chinese and Taiwanese students aged 10-12 with dyslexia against a control from both countries. Participants were asked to rotate a computer 3D model of a field of columns hiding a ball and were then asked to pick the correct location of the ball from the plan. Their results showed no significant difference between the groups with dyslexia and the control on accuracy. They did find a significant difference in answering speed with the participants with dyslexia answering more 
quickly than the controls. This suggests that individuals with dyslexia have improved visualspatial abilities based on faster response times without an increase in error rates.

Brunswick, Martin, and Marzano (2010) found no task in which university-aged students with dyslexia outperformed a control group when using a virtual reality test and a paper-and-pencil test. A sex effect was noted, however. Males with dyslexia outperformed females with dyslexia and unimpaired individuals on a variety of measures. This finding further suggests that superior visual-spatial ability in those with dyslexia may be sex-specific.

Testing the hypothesis that children with dyslexia have enhanced visual-spatial abilities, Duranovic, Dedeic, and Gavrić (2015) used multiple visual-spatial tasks, including the Vandenberg Test of Mental Rotation (1978), and found no significant differences between groups, which suggests that children with dyslexia have similar visual spatial abilities to unimpaired children. In contrast, Winner et al. (2011) found that high school students with dyslexia compared to a non-dyslexic group did not have enhanced visual-spatial skills but rather deficits on many visuospatial tasks. This contradicts results from Duranovic, et al. who found equivalent scores on similar tasks.

Russeler, Scholz, Jordan, and Quaiser-Pohl (2005) aimed to determine the significance of mental rotation ability in children with developmental dyslexia. These researchers compared the mental rotation abilities among children with dyslexia to children without dyslexia. They compared the results from three tests in which letters, three-dimensional figures, and coloured pictures tested the children's mental rotation abilities. Results suggested that children with dyslexia, when compared to the control group, showed a deficient in mental rotation and spatial abilities.

Jones, Branigan, and Kelly (2008) tested dyslexic and non-dyslexic university-level readers' visual attention through a visual-search task and letter position encoding through a symbols task and found significant differences in dyslexic and non-dyslexic readers, in favor of those without dyslexia. These findings support the connection between developmental dyslexia and decreased visual attention ability. Similarly, Facoetti, Corradi, Ruffino, Gori, and Zorzi (2010) tested the phonological, rapid automatized, and visual spatial attention skills in children with familial risk of developmental dyslexia to a group of children without familial risk of developmental dyslexia. Results from a comparison of the two groups suggest that children at risk show a deficit in visual-spatial attention.

Given the importance of spatial ability to mathematics and to future STEM participation, we sought to explore the relationship between children formally identified as having dyslexia and visual-spatial ability and we sought to contribute to the understudied population of school-aged children in grades three to eight. This was the preliminary phase of a sequence of studies that would then ultimately consider the malleability of spatial ability in children with dyslexia.

\section{Participants}

\section{Intended Study}

Students were recruited from 10 elementary schools from a mid-sized urban center. Only students "formally" identified with dyslexia were invited to participate in our research. The list of potential participants was first established by each of the school's special education teacher who oversees education plans provided to students with exceptionalities, and who would have knowledge of those students formally identified.

In our own jurisdiction, there is a distinction between students whose exceptionalities have been identified either formally or informally - and this may also be common in other school boards. A formal identification, as we explain shortly, would have involved psychometric assessments and would be more reliable in our view than informal and perhaps inconsistent identification of students by teachers. For this research, the psychometric 
assessments may have overtly stated "dyslexia" as a diagnosis or would have indicated "difficulties characterized by problems with accurate or fluent word recognition, poor decoding, and poor spelling abilities" (American Psychiatric Association, 2013, p. 67).

In our jurisdiction, parents or the school principal can initiate the formal identification of a student and this occurs through a review and recommendation by the Identification, Placement and Review Committee (IPRC). This committee is legislated to identify exceptional students and to determine an action plan for meeting the needs of the student. The IPRC includes numerous education professionals and formal identification usually involves significant psychometric assessment, usually at the expense of the school board. All psychoeducational assessments of children aged 18 and younger require informed consent from parents. Long delays for school board funded testing of children are often reported by parents and teachers (Blackstock, 2016); consequently, some parents pay for private psychometric assessment to expedite the formal identification (Dunn, 2006).

A student who has been reviewed by the IPRC is considered to be formally identified. An individual education plan (IEP), which outlines the special education program and learning goals for the student, must be completed within 30 school days of a student's formal identification by the IPRC (OME, 2002). The formal identification ensures services and supports for the student because there is an explicit and legal obligation on behalf of the school board to be accountable to the recommendations of the IPRC. This is not to say that those students who have been informally identified are not receiving appropriate services. These students may also have IEPs. However, there is no formal accountability to the IPRC. We surmise that there are advantages for a formal identification or otherwise such a process would not exist. Formal identification creates an obligation by the school to accommodate or modify services and supports based on the needs of the student, and these obligations are not subject to constraints that may arise in terms of budget cutbacks for teaching support, resources, and so forth.

We take the time to explain this process of formal identification in our jurisdiction because our results are directly impacted because of this process. Using conservative population estimates of the prevalence of dyslexia (approximately 4\%), based on the population of students $(n=4138)$ at the 10 elementary schools participating in the study, we anticipated approximately 165 potential participants. Instead, only 25 students were formally identified across the 10 schools, of which 13 parents agreed to allow their child to participate in the study (boys $n=8$, girls $n=5$ ). Participants ranged from the third to eighth grade. Therefore, less than $1 \%$ of the students at these 10 schools were formally identified as having dyslexia and thus officially receiving the supports and services necessary to develop their reading and/or their writing.

\section{Measures and Procedures}

A variety of measures were collected for the students that agreed to participate. These included official school-level achievement data, psychometric assessment, and a demographic questionnaire completed by the parents. The children were then tested individually on different days and in different locations as they were tested at their respective schools. Students were tested on spatial transformations (Levine, Huttenlocher, Taylor, \& Langrock, 1999), the Piagetian Water-Level-Task (Quaiser-Pohl, Lehmann, \& Eid, 2004), the Rod-and-Frame Test (Quaiser-Pohl et al., 2004), and the Vandenberg Mental Rotations Task (MRT) (Quaiser-Pohl et al., 2004; Shepard \& Metzler, 1971; Vandenberg \& Kuse, 1978). The tasks were selected because they were either previously used or had similar properties to in other studies to explore visual-spatial ability and thus the results would enable us to consistently contribute to prior research findings. These tests were also selected because they were easily administered by 
classroom teachers and thus could be used in the future to assist with identifying students if our results should a robust pattern.

Given the very limited amount of participants, and the wide range in ages and grades, we do not report the full results of this testing in this paper given the lack of statistical power in the small sample $(n=11)$. As outlined, our focus shifted to consider why so few students were formally identified and the implications of this unexpected and corollary finding for children with exceptionalities.

\section{Educational Implications}

From the early on during the recruitment period of the research, it became apparent that there were not going to be enough students to compose an adequate sample. However, this led to what may be an even more important question regarding identification of students with learning disabilities and potential equity issues in special education. To make clear, at each of the schools there were students who were informally identified as having reading and/or writing challenges. These students were receiving some level of supports and services if informally identified and we make no judgement on the quality of what is provided for these students. Nevertheless, given our criteria for inclusion in this research, these students were not invited to participate because their diagnosis was not independently confirmed through psychometric assessments and formalized through the IPRC.

It may be that there were, by chance, few students with dyslexia compared to what might be expected. Or, it may be that some parents have declined to have their child formally identified for various reasons, such as fear of stigma. Parents have the right to refuse sharing the psychometric assessments with the school, including any diagnoses (Ontario Psychological Association, 2013). This concern may have contributed partially to the low number of possible participants for our study but, in our view, not sufficiently enough to account fully for the very low number of formally identified students.

In each of the participating schools, we were told consistently and clearly by the special education teachers that quotas existed on the number of students that were funded annually for psychometric assessment. As a result, a plausible explanation is that students who may need to be tested and identified formally are not because of limited funding. Our results raise important ethical questions about who gets tested, who gets identified formally, and to what extent are instances of comorbidity of other learning challenges missed because formal testing and IPRC review is not occurring?

The discrepancy between how many students actually struggle with reading and the number who are formally identified is problematic. Firstly, identification is important because many students have difficulties that extend beyond reading. Dyslexia tends to "co-occur with other disorders, including specific language impairment, speech sound disorder, and attentiondeficit/hyperactivity disorder" (Snowling \& Melby-Lervåg, 2016). Students who are not identified are not only going to continue to struggle with reading, but with potentially other comorbid disorders that are perhaps less obvious, and may impede cognitive and social development in other ways. Consequently, a lack of formal identification may also prevent learning about other challenges that might otherwise go undetected.

For example, a comorbid diagnosis of dyslexia and dyscalculia (i.e., problems processing numerical information, learning arithmetic facts, and performing accurate or fluent calculations) occurs in approximately $40 \%$ to $65 \%$ of identified cases (Barbaresi, Katusic, Colligan, Weaver, \& Jacobsen, 2005; Osisanya et al., 2013; Wilson et al., 2015), despite the fact that they are proposed to have different cognitive profiles (Landerl, Fussenegger, Moll, \& Willburger, 2009). We would assert that children are more likely to be tested for dyslexia than dyscalculia, although no research was found to indicate the prevalence of one over the other.

Brock Education Journal, 26(2), 2017 
Secondly, identification can lead to early intervention, which ensures that the student receives support before they get too far behind their peers. Knivsberg, Reichelt and Nødland (1999) suggest that symptoms become apparent during the pre-school years, meaning that intervention can begin before students have a chance to fall too far behind. Reading skills are crucial in most school disciplines, raising the concern that students with poor reading skills will fall behind in multiple subjects. For example, Beringer et al. (2008) found that students with dyslexia also had problems with both handwriting and written composition, again going back to the comorbidity of disorders. Therefore, early identification ensures that support is available for not only reading, but also all compounding academic difficulties.

Finally, in the absence of formal identification, accountability and the full range of services and supports may not be accessible to a student, or potentially even scaled back in instances where resources are limited. According to Dunn (2006), teacher's observations are not given equal weight to psychoeducational assessments in terms of support recommendations. In fact:

In order for a student to be classified, the standardized assessment scores completed by the school psychologist or speech and language pathologist had to render a profile commensurate with an exceptionality category (e.g., learning disability). If this was not the case, the student would be considered as a slow learner and denied the services he/she needed (Dunn, 2006 ,p. 129).

When recruiting participants for this study, many special education teachers suggested that the sample size could be increased by including those students with IEPs for reading difficulties, despite not being formally diagnosed. While it may be viewed that our inclusion criteria was a limitation of this research, depending on teacher judgment only of learning challenges would have opened up greater concerns over the validity of our participant sample and thus was not considered at any time.

The observation by the special education teachers that more students could be included based on identifications done by teachers, demonstrates that there are students who are informally identified and receiving some level of support. However, the validity of the identification, the extent of the support, and whether the support adequately addresses all the learning challenges of the student would be uncertain without the psychometric assessments and the IPRC review. Moreover, the extent to which the support and services might continue consistently through a child's education and whether these supports and services are scaled back in times of fiscal constraint are unknown. To be clear, we make no rehabilitation judgement; that is, we are not suggesting that formal diagnosis results in beneficial outcomes for the student or more beneficial outcomes than that of an informally identified student. Rather, formal identification results in consistent and sustained learning support services and may also yield comorbid diagnoses.

Perhaps one of the most important reasons that so few formal identifications are occurring is due to the high costs of psychometric assessments, approximately $\$ 1,500$ to $\$ 2,500$ in Ontario (Blackstock, 2016). As a result, many of the schools report that there are restrictions placed on how many students they can recommend for these assessments. For low socioeconomic status (SES) schools in particular, which tend to have higher levels of students with special education needs (People for Education, 2013), sending every student for testing is just not practical. Regardless, parents who can afford the assessments can expedite the process.

Parents of our student participants were also asked in which grade they noticed their child had a reading difficulty and also the grade their child was formally diagnosed. The number of years between the onset of reading difficulties and formal diagnosis was as follows: $15 \% 0$ years, $8 \% 1$ year, $23 \% 2$ years, $38 \% 3$ years, $8 \% 4$ years, and $8 \% 5$ years. Therefore, the majority of children had to wait three years for a formal diagnosis. Evidence from our own small sample of students supports an SES advantage for formal identification. We found that 
$61.5 \%$ of the mothers of participants had some form of post-secondary education, which is said to be a predictor of high SES (Mistry, Biesanz, Chien, Howes, \& Benner, 2008). This means that diagnosis and support goes to perhaps to those who can afford it rather than those who are most in need. Alternatively, parents from higher socioeconomic backgrounds tend to advocate more for their children (Lareau, 1987), and this may offer a partial explanation for the higher SES amongst those children formally identified in the small sample.

Our intent in this research was to examine the visual-spatial abilities of elementary students with dyslexia. Given the mixed research in this area, the importance of visual-spatial reasoning, and its highly malleable nature, this goal is still laudable - and more research is still needed. Our unexpected results of low formal identification suggest that research that comparative research that explores learning and longitudinal socio-economic implications for learners who are formally versus informally identified as having exceptionalities is also, and perhaps urgently, needed. Research of this nature would also investigate the extent to which teacher judgements are sufficient for developing plans of action for special education, in the absence of specialized professional support and recommendations (i.e., educational psychologist). Whether a student is truly marginalized over the long-term by receiving only an "informal" identification is unknown. From an equity perspective, research of this nature should be a priority for all stakeholders, including researchers, parent groups, and also schools.

\section{Acknowledgement}

Sincere thanks to Dr. Kristiina Montero and Dr. Steve Sider, Wilfrid Laurier University, who provided guidance and input to the authors during the research. 
Kotsopoulos, et al. The diagnosis dilemma: Dyslexia and visual-spatial ability

\section{References}

Aleci, C., Piana, G., Piccoli, M., \& Bertolini, M. (2010). Developmental dyslexia and spatial relationship perception. Cortex, 48(4), 466-476.

American Psychiatric Association. (2013). The Diagnostic and Statistical Manual of Mental Disorders, DSM-V (Fourth ed.). Washington: Author.

Barbaresi, W. J., Katusic, S. K., Colligan, R. C., Weaver, A. L., \& Jacobsen, S. J. (2005). Math learning disorder: Incidence in a population-based birth cohort, 1976-82. Ambulatory Pediatrics, 5(5), 281-289.

Berninger, V. W., Nielsen, K. H., Abbott, R. D., Wijsman, E., \& Raskind, W. (2008). Writing problems in developmental dyslexia: Under-recognized and under-treated. Journal of School Psychology, 46(2008), 1-21.

Blackstock, E. (2016). Waitlists for Psychoeducational Assessment in Ontario, http://www.vbpsychology.com/waiting-lists-for-psychoeducational-assessments-inontario: Valetin \& Blackstock Psychology.

Brunswick, N., Martin, G. N., \& Marzano, L. (2010). Visuospatial superiority in developmental dyslexia: Myth or reality? Learning and Individual Differences, 20(5), 421-426.

Casey, B. M., Andrews, N., Schindler, H., Kersh, J. E., Samper, A., \& Copley, J. (2008). The development of spatial skills through interventions involving block building activities. Cognition and Instruction, 26(3), 269-309.

Clements, D. H. (2004). Geometric and spatial thinking in early childhood education. In D. H. Clements, J. Sarama \& A.-M. Di Biase (Eds.), Engaging young children in mathematics: Standards for early childhood mathematics education (pp. 267-298). Mahwah, NJ: Lawrence Earlbaum Associates, Inc.

Dunn, M. W. (2006). It was written all over him: Classroom teachers' referral criteria for special education services. International Journal of Special Education., 21(2), 124139.

Duranovic, M., Dedeic, M., \& Gavrić, M. (2015). Dyslexia and visual-spatial talents. Current Psychology, 34(2), 207-222.

Facoetti, A., Corradi, N., Ruffino, M., Gori, S., \& Zorzi, M. (2010). Visual spatial attention and speech segmentation are both impaired in preschoolers at familial risk for developmental dyslexia. Dyslexia. , 16(3), 226-239.

Jones, M. W., Branigan, H. P., \& Kelly, M. L. (2008). Visual deficits in developmental dyslexia: relationships between non-linguistic visual tasks and their contribution to components of reading. Dyslexia, 14(2), 95-115.

Knivsberg, A., Reichelt, K., \& Nødland, M. (1999). Comorbidity, or coexistence, between dyslexia and attention deficit hyperactivity disorder. British Journal of Special Education, 26(1), 42-47.

Landerl, K., Fussenegger, B., Moll, K., \& Willburger, E. (2009). Dyslexia and dyscalculia: Two learning disorders with different cognitive profiles. Journal of Experimental Child Psychology, 103(3), 309-324.

Lareau, A. (1987). Social class differences in family-cchool relationships: The importance of cultural capital. Sociology of Education, 60(2), 73-85.

Levine, S. C., Huttenlocher, J., Taylor, A., \& Langrock, A. (1999). Early sex differences in spatial skill. Developmental psychology, 35(4), 940.

Linn, M. C., \& Peterson, A. C. (1985). Emergence and characterization of sex differences in spatial ability: A metaanalysis. Child Development, 56, 1479-1498.

Lubinski, D. (2010). Spatial ability and STEM: A sleeping giant for talent identification and development. Personality and Individual Differences, 49, 344-351. 
Kotsopoulos, et al. The diagnosis dilemma: Dyslexia and visual-spatial ability

Mistry, R. S., Biesanz, J. C., Chien, N., Howes, C., \& Benner, A. D. (2008). Socioeconomic status, parental investments, and the cognitive and behavioral outcomes of lowincome children from immigrant and native households. Early Childhood Research Quarterly, 23(2), 193-212.

Newcombe, N. S. (2010). Picture this: Increasing math and science learning by improving spatial thinking. American Educator, 34(2), 29-43.

OME. (2002). The Individual Education Plan (IEP): A Resource Guide. Toronto, ON.

Ontario Psychological Association. (2013). Professional practice guidelines for school psychologists in Ontario [Electronic Version]. Retrieved August 16, 2016, from http://psych.on.ca/OPA/media/Public/OPA\%20Guidelines\%20and\%20Reviews/profe ssional-practice-guidelines-for-school-psychologists-in-ontario-2013.pdf

Osisanya, A., Lazarus, K., \& Adewunmi, A. (2013). Manifestations of dyslexia and dyscalculia. Journal of International Special Needs Education, 16(1), 40-52.

People for Education. (2013). Mind the Gap: Inequality in Ontario's Schools. from http://www.peopleforeducation.ca/wp-content/uploads/2013/05/annual-report-2013WEB.pdf

Quaiser-Pohl, C., Lehmann, W., \& Eid, M. (2004). The relationship between spatial abilities and representations of large-scale space in children--a structural equation modeling analysis. Personality and Individual Differences, 36(1), 95-107.

Rüsseler, J., Scholz, J., Jordan, K., \& Quaiser-Pohl, C. (2005). Mental rotation of letters, pictures, and three-dimensional objects in German dyslexic children. Child Neuropsychology, 11(6), 497-512.

Shepard, R. N., \& Metzler, J. (1971). Mental rotation of three-dimensional objects. Science, $171,701-703$.

Snowling, M. J., \& Melby-Lervåg, M. (2016). Oral language deficits in familial dyslexia: A meta-analysis and review. Psychological Bulletin, 1-48.

Tolar, T. D., Lederberg, A. R., \& Fletcher, J. M. (2009). A structural model of algebra achievement: Computational fluency and spatial visualisation as mediators of the effect of working memory on algebra achievement. Educational Psychology, 29(2), 239-266.

Uttal, D. H., Meadow, N. G., Tipton, E., Hand, L. L., Alden, A. R., Warren, C., et al. (2013). The malleability of spatial skills: A meta-analysis of training studies. Psychological Bulletin, 139(2), 352-402.

Vandenberg, S. G., \& Kuse, A. R. (1978). Mental rotations. A group test of threedimensional spatial visualization. Perceptual and Motor Skills, 47, 599-604.

Wai, J., Lubinski, D., \& Benbow, C. P. (2009). Spatial ability for STEM domains: Aligning over 50 years of cumulative psychological knowledge solidifies its importance. Journal for Educational Psychology, 101(4), 817-835.

Wang, L., \& Yang, H. (2011). The comparison of the visuo-spatial abilities of dyslexic and normal students in Taiwan and Hong Kong. Research in developmental disabilities, 32(3), 1052-1057.

Wilson, A. J., Andrewes, S. G., Struthers, H., Rowe, V. M., Bogdanovic, R., \& Waldie, K. E. (2015). Dyscalculia and dyslexia in adults: Cognitive bases of comorbidity. Learning and Individual Differences, 37(0), 118-132.

Winner, E., von Karolyi, C., Malinsky, D., French, L., Seliger, C., \& Ross, E. (2011). Dyslexia and visual-spatial talents: Compensation vs deficit model. Brain and Language, 76(2), 81-110. 